\title{
Pengaruh Padat Penebaran Yang Berbeda Terhadap Pertumbuhan Panjang Dan Bobot Serta Sintasan Juwana Kuda Laut (Hippocampus Barbouri)
}

\author{
Muhammad Syukri*) \\ Universitas Sulawesi Barat \\ e-mail : ukey_achiek@yahoo.com
}

\begin{abstract}
Abstrak
Penelitian ini bertujuan untuk Untuk mengetahui pengaruh padat penebaran terhadap pertumbuhan panjang dan bobot serta sintasan juwana kuda laut (Hippocampus barbouri). Hasil dari penelitian ini diharapkan dapat menjadi bahan informasi bagi pengembangan pembenihan dan berbagai penelitian selanjutnya. Selain itu dapat digunakan untuk budidaya, restocking, dan penangkaran di laut untuk tujuan komersil. Penelitian ini menggunakan 4 perlakuan dengan 3 kali ulangan sehingga terdapat 12 satuan percobaan, dimana ukuran juwana kuda laut yang digunakan memiliki kisaran panjang awal 1,36 cm, sedangkan rata-rata bobot juwana pada wal penelitian yaitu 0.020 gram. Juwana kuda laut dipelihara selama 30 hari. Pakan yang diberikan berupa Artemia salina dengan kepadatan 1 ekor/ml dan frekuensi pemberian pakan 3 kali sehari. Pengukuran pertumbuhan panjang dan bobot dilakukan setiap 7 hari dengan mengukur panjang tubuh juwana kuda laut yang diukur dari mahkota hingga ujung ekor secara tegak lurus serta menimbang bobot tubuh juwana kuda laut dengan menggunakan timbangan elektrik dengan ketelitian 0,1 gram, sedangkan Pengamatan sintasan dilakukan pada akhir penelitian dengan menghitung jumlah juwana kuda laut yang hidup. Pengukuran kualitas air juga dilakukan setiap hari, kecuali pengukuran kadar amoniak ( $\left.\mathrm{NH}_{3}\right)$ dilakukan setiap 7 hari pada saat pengukuran pertumbuhan juwana kuda laut. Hasil penelitian menunjukkan bahwa Padat penebaran yang berbeda tidak memberikan pengaruh nyata terhadap laju pertumbuhan panjang dan bobot juwana kuda laut (Hippocampus barbouri), sedangkan Padat penebaran yang berbeda memberikan pengaruh yang nyata terhadap sintasan juwana kuda laut (Hippocampus barbouri), dimana Sintasan yang tertinggi untuk pemeliharaan juwana kuda laut diperoleh pada padat penebaran 2 ekor/liter.
\end{abstract}

Kata kunci : Padat penebaran, pertumbuhan panjang, bobot dan sintasan.

\section{PENDAHULUAN}

Menurut Widodo $d k k$ (1998), perairan Indonesia merupakan daerah terkaya akan jenisjenis ikan hias laut dibandingkan dengan beberapa negara penghasil ikan hias lainnya. Di Indonesia sendiri terdapat lebih kurang 253 jenis ikan hias laut, salah satunya adalah kuda laut. Kuda laut cukup komersial dan unik karena mempunyai morfologi yang berbeda dengan ikan ikan yang lain yaitu bentuk kepalanya menyerupai kepala kuda dan ikan jantan mempunyai kantung pengeraman yang tidak dijumpai pada jenis ikan yang lain. Daya tarik lain adalah 
posisi badannya yang tegak saat berenang serta kemampuan untuk menyesuaikan warna tubuhnya dengan lingkungan sehingga penampilannya makin menarik untuk pajangan di akuarium. Manfaat lain dari kuda laut adalah sebagai bahan baku obat - obatan tradisional dan souvenir.

Indonesia sebagai negara maritim dengan dua pertiga luas wilayahnya berupa perairan, memiliki potensi ikan hias yang cukup beragam, dengan 253 jenis ikan hias, menjadikan Indonesia negara terkaya di dunia untuk penghasil ikan hias dibandingkan dengan negara tropik yang lainnya. Kuda laut (Hippocampus sp) merupakan salah satu jenis ikan hias yang terdapat di Indonesia (NAFED, 1993) dan merupakan salah satu jenis ikan hias yang bernilai tinggi. Selain untuk kebutuhan pasar dalam negeri juga memasuki pasaran luar negeri. Setiap tahunnya tidak kurang dari 20 juta ekor kuda laut kering dan ratusan ribu kuda laut hidup ditangkap dan diperdagangkan oleh kurang lebih 40 negara, termasuk Indonesia. Negara pengekspor kuda laut di dunia, yaitu Cina, Taiwan, Hongkong, Thailand, Vietnam, India, Filipina, dan Indonesia (Vincent, 1998). Pemasaran kuda laut bisa dilakukan dalam keadaan hidup untuk ikan hias, juga dijual kering sebagai bahan ramuan obat tradisional untuk mengobati keluhan-keluhan seksual (Al Qodri, 1997). Kuda laut juga dimanfaatkan sebagai ikan hias akuarium dan souvenir (Vincent, 1996).

Hal tersebut yang mendorong terjadinya penangkapan yang intensif di alam sehingga membahayakan kelestariannya. Salah satu upaya yang dilakukan untuk menjaga kelestarian kuda laut, yaitu dengan melakukan pengembangan ke arah budidaya. Salah satu aspek budidaya yang perlu diketahui terhadap kondisi suatu jasad akuatik yaitu padat penebaran. Umur dan ukuran suatu spesies merupakan faktor yang menentukan padat penebaran dalam menghasilkan produksi yang optimum (Mangampa $d k k$., 2002).

Penelitian sebelumnya oleh Sudaryanto dan Al Qodri, memperoleh sintasan 30\% pada hari ke 11-15 dengan kepadatan awal 1000-1500 ekor/ton. Sudaryanto (1995) mendapatkan sintasan 23,3-38,5\% yang dipelihara selama 30 hari. Al Qodri (1997) mendapatkan sintasan $38,4 \%$ dari beberapa kali pemeliharaan juwana kuda laut hingga umur 30 hari dengan kepadatan awal 500-1500 ekor/ton.

Beberapa penelitian yang telah dilakukan di atas belum memberikan hasil yang maksimal, sehingga perlu dilakukan penelitian tentang pemeliharaan juwana kuda laut dalam wadah terkontrol pada padat penebaran yang berbeda, yang akan menunjang pengembangan pembenihan hingga ke arah pembudidayaan.

Kuda laut adalah hewan yang telah mengalami evolusi sejak 40 juta tahun lalu (Fritzhe, 1997). Diistilahkan ke dalam genus Hippocampus karena berasal dari bahasa Yunani yang berarti binatang laut berbentuk kepala kuda, (hippos $=$ kepala kuda ; campus $=$ binatang laut).

Di Indonesia kuda laut dikenal dengan sebutan tangkur kuda yang merupakan salah satu jenis ikan laut kecil yang sangat berbeda dengan jenis ikan lainnya yaitu kepala kuda laut mempunyai mahkota, tubuh agak pipih dan melengkung, seluruh tubuh terbungkus oleh semacam baju baja yang terdiri atas lempengan - lempengan tulang atau cincin - cincin, mata kecil dan sama lebar, mempunyai moncong, ekor lebih panjang dari kepala dan tubuh serta dapat memegang, sirip dada pendek dan lebar, sirip punggung cukup besar, sedang sirip anal kecil dan sirip ekor tidak ada (Nontji 1993).

Kuda laut adalah hewan yang telah mengalami evolusi sejak 40 juta tahun yang lalu. Kuda laut ini termasuk dalam genus Hippocampus dari famili Syngnathidae, ordo Gasterosteiformes (Al Qodri $d k k$., 1997). 
JURNAL SAINTIFIK VOL.2 NO.2, JULI 2016

Taksonomi kuda laut menurut Hidayat dan Silvester (1998) ialah sebagai berikut :

Phylum : Chordata

Sub Phylum:Vertebrata

Kelas : Pisces

Ordo : Gasterosteiformes

Famili : Syngnathidae

Genus : Hippocampus

Spesies :Hippocampus barbouri

\section{METODOLOGI}

Penelitian ini dilaksanakan di Balai Perikanan Budidadaya Air Payau (BPBAP) Takalar, Desa Meppakalompo Kecamatan Galesong Selatan Kabupaten Takalar Provinsi Sulawesi Selatan.

Sebagai tahap awal penelitian dilakukan persiapan dengan menyiapkan wadah dan alatalat yang digunakan dalam penelitian. Untuk treatment air, dengan menggunakan saringan catridge filter dan filter bag 1 mikron. Setiap wadah dilengkapi dengan aerasi dan shelter/subtrat tempat juwana melilitkan ekornya.

Selanjutnya wadah penelitian terlebih dahulu dipersiapkan wadah penelitian yang akan digunakan yaitu ; akuarium kaca berukuran $60 \times 80 \times 60 \mathrm{~cm}^{3}$ sebanyak 10 buah untuk adaptasi induk. Untuk pemeliharaan dan pemijahan induk kuda laut digunakan akuarium kaca berukuran $50 \times 35 \times 34 \mathrm{~cm}^{3}$ sebanyak 12 buah. Akuarium kecil berukuran $20 \times 20 \times 20 \mathrm{~cm}^{3}$ sebanyak 12 buah dipergunakan untuk pemeliharaan juwana. Setiap wadah percobaan dilengkapi dengan sistem filter, aerasi dan tempat bertengger (shelter).

Induk kuda laut yang dipijahkan di BPBAP Takalar diperoleh dari Pulau Lantang Peo Kepulauan Tanakeke dari hasil tangkapan nelayan dengan panjang rata-rata induk jantan dan induk betina berkisar $12-13 \mathrm{~cm}$. Induk yang telah diambil terlebih dahulu dimasukkan ke dalam wadah akuarium yang berukuran $80 \times 60 \times 60 \mathrm{~cm}^{3}$ yang telah disiapkan sebelumnya untuk diadaptasikan selama 1 Minggu setelah itu dimasukkan ke dalam akuarium berukuran 50 x $35 \times 34 \mathrm{~cm}^{3}$ dengan perbandingan 1: 1. Pakan yang diberikan berupa jembret (Mesopodopsis sp) dengan frekuensi 2 x sehari secara ad libitum.

Pemeliharaan Juwana kuda laut yang diperoleh dari pemijahan dimasukkan ke dalam wadah penelitian berupa akuarium yang berukuran $20 \times 20 \times 20 \mathrm{~cm}^{3}$ dengan padat penebaran yang berbeda sesuai dengan perlakuan. Rata-rata panjang juwana yaitu $1.36 \mathrm{~cm}$ dengan kisaran panjang $1.30 \mathrm{~cm}-1.40 \mathrm{~cm}$, sedangkan rata-rata bobot juwana yaitu 0.02 gram. Juwana kuda laut dipelihara selama 30 hari. Pakan yang diberikan berupa Artemia salina dengan kepadatan 1 ekor/ml dan frekuensi pemberian pakan 3 kali sehari.

Rancangan percobaan yang digunakan dalam penelitian ini yaitu Rancangan Acak Lengkap (RAL) dengan 4 perlakuan dan 3 kali ulangan sebagai berikut :

- Perlakuan $\mathrm{A}=$ Padat penebaran 2 ekor/liter

- Perlakuan $\mathrm{B}=$ Padat penebaran 3 ekor/liter

- Perlakuan $\mathrm{C}=$ Padat penebaran 4 ekor/liter

- Perlakuan $\mathrm{D}=$ Padat penebaran 5 ekor/liter 
Terdapat 12 unit satuan percobaan yang selanjutnya wadah percobaan diletakkan secara acak. Letak unit percobaan setelah pengacakan dapat dilihat pada Gambar 2.

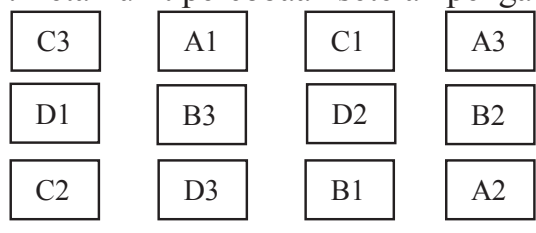

Gambar 1. Tata letak wadah penelitian

Pengukuran pertumbuhan panjang dan bobot dilakukan setiap 7 hari dengan mengukur panjang tubuh juwana kuda laut yang diukur dengan menggunakan mistar ukur dari mahkota hingga ujung ekor secara tegak lurus serta menimbang bobot tubuh juwana kuda laut dengan menggunakan timbangan elektrik dengan ketelitian 0,1 gram.

Untuk menghitung laju pertumbuhan bobot/berat dan panjang individu harian juwana kuda laut, digunakan rumus Huisman (1976) :

1. Laju Pertumbuhan Bobot/Berat Individu Harian Juwana Kuda Laut

$\mathbf{W t}=\mathrm{Wo}_{\mathbf{0}}(\mathbf{1}+\mathbf{0 , 0 1} \alpha)^{\mathbf{t}}$

Ket : $\alpha=$ Persentase pertumbuhan harian (\%)

Wo $=$ Bobot rata-rata juwana waktu ke-o $(\mathrm{g})$

$\mathrm{Wt}=$ Bobot rata-rata juwana waktu ke-t $(\mathrm{g})$

$\mathrm{t}=$ Waktu pengamatan (hari)

2. Laju Pertumbuhan Panjang Individu Harian Juwana Kuda Laut

$\mathbf{L t}=\mathbf{L o}(1+0,01 \alpha)^{t}$

Ket : $\alpha=$ Persentase pertumbuhan harian (\%)

Lo $=$ Panjang rata-rata juwana waktu ke-o $(\mathrm{g})$

$\mathrm{Lt}=$ Panjang rata-rata juwana waktu ke-t $(\mathrm{g})$

$\mathrm{t}=$ Waktu pengamatan (hari)

3. Sintasan

Pengamatan sintasan dilakukan pada akhir penelitian dengan menghitung jumlah juwana kuda laut yang hidup.

$\mathrm{SR}=\frac{\mathrm{Nt}}{\mathrm{No}} \times 100 \%$

Ket : SR $=$ Sintasan $(\%)$

No $=$ Jumlah juwana pada awal percobaan (ekor)

$\mathrm{Nt}=$ Jumlah juwana hidup pada akhir percobaan (ekor)

4. Kualitas Air

Sebagai data penunjang dilakukan pengukuran parameter kualitas air yang meliputi : salinitas, suhu, $\mathrm{pH}$ dan oksigen terlarut yang dilakukan setiap hari. Sedangkan pengukuran kadar Amoniak $\left(\mathrm{NH}_{3}\right)$ dilakukan setiap 7 hari pada saat pengukuran pertumbuhan juwana kuda laut. Selain itu, juga dilakukan penyiponan dasar wadah dari kotoran dan sisa pakan yang mati. 


\section{JURNAL SAINTIFIK VOL.2 NO.2, JULI 2016}

Untuk mengetahui pengaruh padat penebaran terhadap pertumbuhan dan sintasan juwana kuda laut digunakan analisis ragam. Apabila perlakuan berpengaruh nyata terhadap pertumbuhan dan sintasan kuda laut, maka dilanjutkan dengan uji Beda Nyata Terkecil (Hanafiah, 1995) untuk mengetahui perlakuan yang terbaik.

\section{HASIL DAN PEMBAHASAN}

\section{Laju Pertumbuhan Panjang dan Bobot}

Pertumbuhan panjang dan bobot juwana kuda laut yang diperoleh selama penelitian dari masing-masing perlakuan dapat dilihat pada Gambar 3 dan 4. Pada Gambar 3 terlihat bahwa pertumbuhan panjang juwana kuda laut semakin meningkat seiring dengan bertambahnya waktu penelitian yaitu dari rata-rata panjang awal $1.36 \mathrm{~cm}$ pada awal penelitian, mencapai panjang rata-rata $3.25 \mathrm{~cm}$ untuk perlakuan $\mathrm{A}, 3.21 \mathrm{~cm}$ untuk perlakuan $\mathrm{B}, 3.08 \mathrm{~cm}$ untuk perlakuan $\mathrm{C}$, dan $3.06 \mathrm{~cm}$ untuk perlakuan D. Lebih jelasnya dapat dilihat pada gambar 3 berikut.

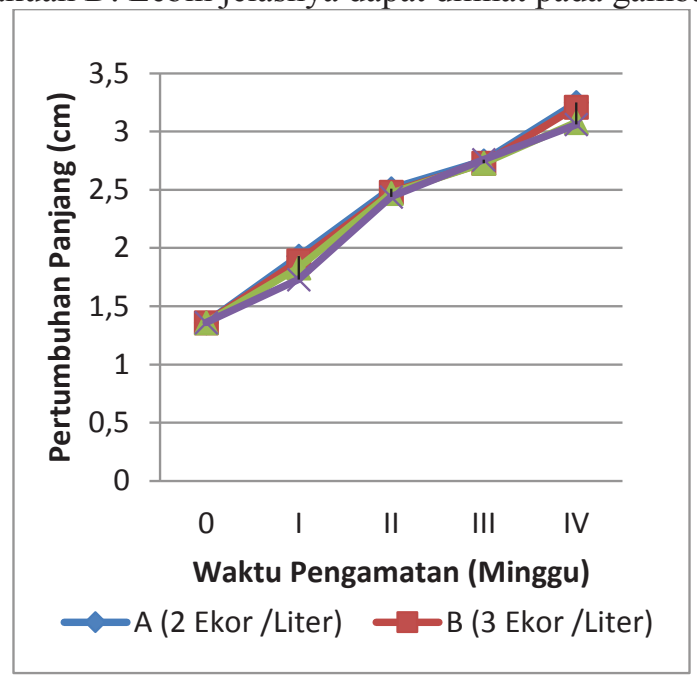

Gambar 2. Rata-rata Pertumbuhan Panjang Juwana Kuda Laut

Pada gambar 4 menunjukkan bahwa pertumbuhan bobot juwana kuda laut dari berat awal rata-rata 0.020 gram pada awal penelitian mencapai bobot rata-rata 0.138 untuk perlakuan A, 0.132 untuk perlakuan $\mathrm{B}, 0.108$ untuk perlakuan $\mathrm{C}$, dan 0.103 untuk perlakuan D pada akhir penelitian. 


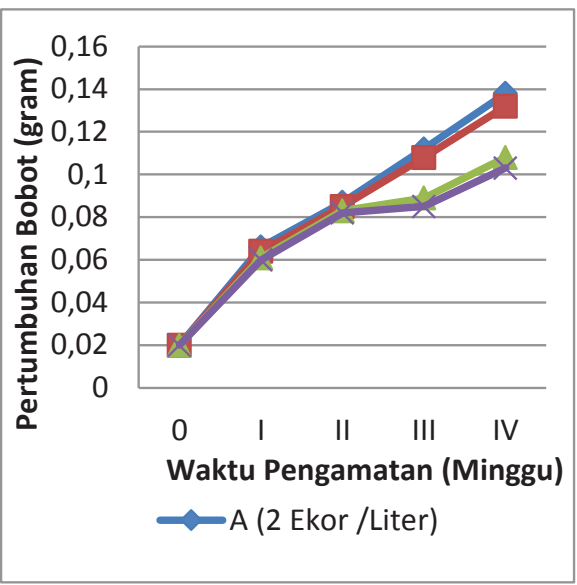

Gambar 3. Rata-rata Pertumbuhan Bobot Juwana Kuda Laut

Rata-rata laju pertumbuhan panjang dan bobot juwana kuda laut selama penelitian dapat dilihat pada Tabel 3, hal ini menunjukkan bahwa padat penebaran yang berbeda tidak berpengaruh nyata, baik terhadap laju pertumbuhan panjang harian, maupun laju pertumbuhan bobot harian juwana kuda laut. Hal ini disebabkan karena pada perlakuan $\mathrm{C}$ dan $\mathrm{D}$ terjadi kematian juwana kuda laut sebanyak $\pm 45 \%$, maka akan sama kepadatannya dengan perlakuan A dan B. Sehingga dengan kepadatan yang sama, jumlah makanan yang diberikan pada masing-masing perlakuan sama dan menyebabkan pertumbuhan panjang dan bobot juwana kuda laut tidak berbeda.

Tabel 1.Rata-rata Laju Pertumbuhan Panjang dan Bobot, serta Sintasan Juwana Kuda Laut

\begin{tabular}{|c|c|c|c|c|}
\hline \multirow{2}{*}{ PARAMETER } & \multicolumn{4}{|c|}{ PERLAKUAN } \\
\hline & $\begin{array}{c}\text { A (2 } \\
\text { ekor } \\
\text { /liter) }\end{array}$ & $\begin{array}{c}\text { B (3 } \\
\text { ekor } \\
\text { /liter } \\
\text { ) }\end{array}$ & $\begin{array}{c}\text { C (4 } \\
\text { ekor } \\
\text { /liter) }\end{array}$ & $\begin{array}{c}\text { D (5 } \\
\text { ekor } \\
\text { /liter) }\end{array}$ \\
\hline $\begin{array}{c}\text { Laju } \\
\text { Pertumbuhan } \\
\text { Panjang Juwana } \\
\text { Kuda Laut (\%) }\end{array}$ & $\begin{array}{c}3.041 \\
\pm \\
0.083^{\mathrm{a}}\end{array}$ & $\begin{array}{l}2.96 \\
1 \pm \\
0.06 \\
2^{\mathrm{a}}\end{array}$ & $\begin{array}{l}2.894 \\
\pm \\
0.039^{\mathrm{a}}\end{array}$ & $\begin{array}{l}2.962 \\
\pm 0.093 \\
\text { a }\end{array}$ \\
\hline Laju & 7.158 & 6.23 & 5.917 & 5.978 \\
\hline Pertumbuhan & \pm & $6 \pm$ & \pm & \pm 0.353 \\
\hline Bobot Juwana & $0.143^{\mathrm{a}}$ & 0.31 & $0.459^{\mathrm{a}}$ & a \\
\hline
\end{tabular}


JURNAL SAINTIFIK VOL.2 NO.2, JULI 2016

\begin{tabular}{|c|c|c|c|c|}
\hline Kuda Laut (\%) & & $7^{\mathrm{a}}$ & & \\
& & & & \\
\hline & 85.35 & 83.2 & $65.58 \pm$ & 63.12 \\
Sintasan Juwana & \pm & $3 \pm$ & 12.729 & \pm 9.547 \\
Kuda Laut (\%) & 14.437 & 7.21 & bc & c \\
& a & $5^{\mathrm{a}}$ & & \\
\hline
\end{tabular}

Keterangan: ${ }^{a}$ huruf yang sama dalam baris menunjukkan perlakuan tidak berpengaruh nyata $(\mathrm{P}$ $>0.05)$

\section{Sintasan}

Hasil percobaan yang dilakukan selama penelitian diperoleh sintasan $85.35 \%$ untuk perlakuan A, 83,23\% untuk perlakuan B, $65.58 \%$ untuk perlakuan $\mathrm{C}$, dan $63.12 \%$ untuk perlakuan D. Hasil analisis ragam sintasan juwana kuda laut memperlihatkan bahwa terdapat perbedaan yang signifikan di antara perlakuan A, B, C, dan D. Setelah dilanjutkan dengan Uji Beda Nyata Terkecil maka diperoleh bahwa antara perlakuan A dan B tidak berbeda nyata, perlakuan A dan C berbeda nyata, perlakuan A dan D berbeda sangat nyata, perlakuan B dan C berbeda nyata, perlakuan B dan D berbeda sangat nyata, sedangkan perlakuan $\mathrm{C}$ dan D tidak berbeda nyata. Dengan demikian penebaran 2 dan 3 ekor/liter memberikan pengaruh yang sama terhadap sintasan.

Padat penebaran tidak berbeda nyata terhadap pertumbuhan panjang dan bobot juwana kuda laut, tetapi berbeda nyata terhadap sintasan juwana kuda laut. Hal ini disebabkan karena dengan pemberian pakan $2 \mathrm{ekor} / \mathrm{ml}$ terhadap setiap perlakuan, energi tersebut hanya dipakai untuk bertahan hidup, tetapi kurang mampu dipakai untuk bertumbuh.

Semua perlakuan bertumbuh dan tidak berbeda antar perlakuan. Rendahnya sintasan pada perlakuan C dan D karena terbatasnya jumlah makanan. Selain itu kuda laut merupakan hewan pemangsa pasif yang hanya menunggu makanan lewat di sampingnya lalu menyerangnya dengan menggunakan moncongnya yang panjang, diduga menjadi salah satu faktor yang menyebabkan rendahnya sintasan pada perlakuan $\mathrm{C}$ dan D. Hal ini disebabkan karena peluang pada perlakuan $\mathrm{C}$ dan $\mathrm{D}$ yang rendah untuk mendapatkan makanan ketika ditebar dalam kepadatan yang tinggi. Hal tersebut dapat dilihat pada gambar 5 berikut. 


\section{Kualitas Air}

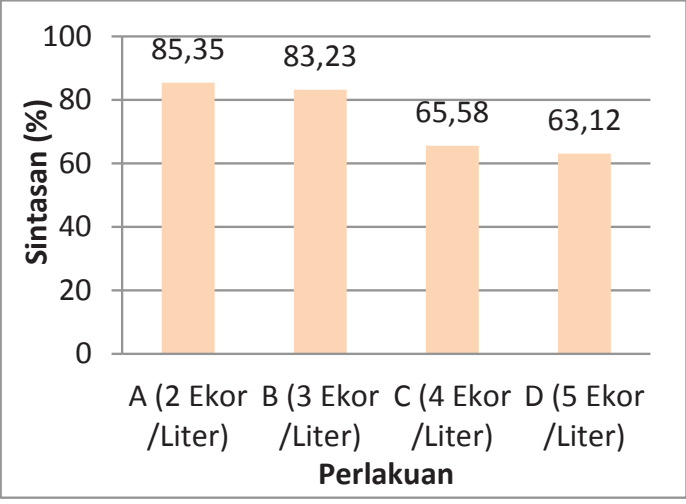

Gambar 5. Rata-rata Sintasan Juwana Kuda Laut Setiap Perlakuan

Kualitas air merupakan salah satu faktor yang penting dalam pemeliharaan kuda laut. Hasil pengukuran parameter kualitas air rata-rata seperti suhu, salinitas, oksigen terlarut, $\mathrm{pH}$, dan amoniak berada dalam kisaran yang layak untuk kehidupan juwana kuda laut dapat dilihat pada Tabel 2.

Tabel 2.Rata-rata Hasil Pengukuran Parameter Kualitas Air Pemeliharaan Juwana Kuda Laut

\begin{tabular}{|c|c|c|c|c|c|c|}
\hline No & $\begin{array}{c}\text { erlak } \\
\text { uan }\end{array}$ & uhu & $\begin{array}{c}\text { alinitas } \\
\text { (ppt) }\end{array}$ & $\mathbf{H}$ & $\mathbf{O}$ & $\begin{array}{c}\text { mo } \\
\text { niak } \\
\mathbf{( p p} \\
\mathbf{m})\end{array}$ \\
\hline$\cdot$ & & 7 & 5 & .56 & .74 & $\begin{array}{c}.003 \\
0\end{array}$ \\
\hline$\cdot$ & & 7 & 5 & .54 & .72 & $\begin{array}{c}.003 \\
\mathbf{m g} / \mathbf{L})\end{array}$ \\
\hline$\cdot$ & & 7 & 5 & .52 & .68 & .003 \\
\hline & & & & & & 7 \\
\hline
\end{tabular}

Rata-rata suhu air selama pemeliharaan adalah $26^{\circ} \mathrm{C}$. Pemeliharaan kuda laut pada suhu yang melampaui batas toleransinya akan menyebabkan kematian total (Dao dan Hoang, 1991). Menurut Al Qodri dkk (1997), kisaran suhu yang layak untuk pemeliharaan kuda laut adalah $26^{\circ} \mathrm{C}-28^{\circ} \mathrm{C}$, kuda laut muda mempunyai batas toleransi suhu yang sempit dibandingkan dengan kuda laut dewasa (Zhang, 1994). 
JURNAL SAINTIFIK VOL.2 NO.2, JULI 2016

Salinitas air selama pemeliharaan adalah 35 ppt. Moren (1998), melaporkan bahwa berdasarkan hasil kajiannya pada beberapa literatur kuda laut dapat hidup pada salinitas $15 \mathrm{ppt}$ sampai 35 ppt, namun sebagian kuda laut dipelihara pada salinitas $30 \mathrm{ppt}-35 \mathrm{ppt}$. AIS (1982) menambahkan bahwa batas toleransi sallinitas untuk kuda laut muda lebih sempit dibandingkan dengan kuda laut dewasa.

Rata-rata derajat keasaman $(\mathrm{pH})$ selama pemeliharaan adalah 7.56 untuk perlakuan A, 7.54 untuk perlakuan B, 7.52 untuk perlakuan C, dan 7.51 untuk perlakuan D. Fluktuasi $\mathrm{pH}$ yang luas sangat berisiko pada pembudidayaan kuda laut. Kadar $\mathrm{pH}$ yang paling baik adalah 7 -8 (Anonymous, 1990).

Pemberian Oksigen dengan menggunakan aerasi selama pemeliharaan mampu mendukung tersuplainya Oksigen dengan baik. Oksigen terlarut selama pemeliharaan adalah $5.74 \mathrm{mg} / \mathrm{L}$ untuk perlakuan A, $5.72 \mathrm{mg} / \mathrm{L}$ untuk perlakuan B, $5.68 \mathrm{mg} / \mathrm{L}$ untuk perlakuan $\mathrm{C}$, dan $5.65 \mathrm{mg} / \mathrm{L}$ untuk perlakuan D. Kisaran ini masih tergolong layak untuk kehidupan juwana kuda laut sebagaimana yang dinyatakan oleh Al Qodri (1997), bahwa kisaran Oksigen terlarut untuk kehidupan juwana kuda laut adalah $5-6 \mathrm{mg} / \mathrm{L}$. AIS (1982) menambahkan bahwa untuk induk jantan dan sedang hamil (mengeram) dan kuda laut muda pada masa pertumbuhan membutuhkan konsentrasi oksigen terlarut yang lebih tinggi.

Rata-rata kandungan amoniak selama pemeliharaan adalah $0.0030 \mathrm{ppm}$ untuk perlakuan A, 0.0035 ppm untuk perlakuan $\mathrm{B}, 0.0037 \mathrm{ppm}$ untuk perlakuan $\mathrm{C}$, dan 0.0041 untuk perlakuan D. Agar kandungan amoniak dalam media pemeliharaan tidak meningkat maka dilakukan penyiponan terhadap sisa-sisa pakan dan feces kuda laut setiap 2 hari sebelum diberi makan. Kadar amoniak yang cocok untuk pemeliharaan kuda laut adalah $<0.05$ ppm (Al Qodri, 1998). Sedangkan menurut Boyd (1979) bahwa kisaran amoniak yang aman untuk kelangsungan hidup kuda laut adalah $0.01 \mathrm{ppm}$. Hal tersebut menunjukkan dalam wadah pemeliharaan kandungan amoniaknya masih tergolong sesuai untuk kelangsungan hidup kuda laut.

\section{KESIMPULAN}

Kesimpulan

1. Padat penebaran yang berbeda tidak memberikan pengaruh nyata terhadap laju pertumbuhan panjang dan bobot juwana kuda laut (Hippocampus barbouri),

2. Padat penebaran yang berbeda memberikan pengaruh yang nyata terhadap sintasan juwana kuda laut (Hippocampus barbouri).

3. Sintasan yang tertinggi untuk pemeliharaan juwana kuda laut diperoleh pada padat penebaran 2 ekor/liter.

\section{DAFTAR PUSTAKA}

AIS (Aquaculture Institute of Shanghai). 1982. Culture of Seahorse. pp. $474-495$ in : Fish Biology and Mariculture. Agriculture Publication Press, Beijing.

Al Qodri, A.H., Sudjiharno dan P. Hartono. 1997. Rekayasa Teknologi Pembenihan Kuda Laut (Hippocampus spp). Ditjen Balai Budidaya Laut. Lampung. 
Al Qodri, A.H. 1998. Breeding Standart of Seahorse in Indonesia Presented to International Workshop on The Management and Culture of Marine Species Used in Traditional Medicine - Cebu. Philippines

Al Qodri, A.H., Sudjiharno dan P. Hartono. 1999. Paket Usaha Budidaya Kuda Laut (Hippocampus spp). Disampaikan pada Pertemuan Sosialisasi Rekayasa Teknologi UPT. Ditjen Perikanan Cisarua Bogor. 4 - 6 Agustus 1999.

Anonim. 1998. Pembenihan Kuda Laut (Hippocampus spp). Departemen Pertanian Direktorat Jenderal Perikanan. Balai Budidaya Laut Lampung. Lampung.

Anonymous. 1990. Seahorse Culture In North China Saltpan. China Aquaculture, Shanghai.

Boyd, C.F. 1979. Water Quality in Warm Water Fish Pond. Auburn University. Alabama.

Chamberlain, B.W. 1988. Technical Bulletin. Tinjauan Kembali Pengelolaan Tambak Udang. Texas A and N Research and Extention Center American. 48 -69.

Cowey, E.M. and J.R. Sargent. 1972. Fish Nutrition . P 383-492. in Russel, F.S and Yonge (eds). Advances in Marine Biology. Academic Press. London.

Danakusumah, E. dan K. Imanishi. 1984. On The Station of Grouper (Epinephelus tawrina). Laporan Penelitian Perikanan Laut (30) : 63-66.

Dao, X.L. dan P. Hoang. 1991. Result of the Surveys of Hippocampus Sea Horses in the Coastal Areas of Central Provinces and the Breeding of Hippocampus kuda Sea Horse in Cement Tanks. Nha Trang Oceanographic Reseach Institute.

Fritzche, R. A., 1997. Revision Of The Eastern Pacific Syngnathidae (Pisces : Syngnathiformes), Including Both Recent And Fossil Forms. Proceeding Of The California Academy Of Sciences. http://www.oceanoasis.org/fieldguide/hipp-ing.html (diakses 18 Agustus 2015).

Hanafiah, K.A., MS. 1995. Rancangan Percobaan : Teori dan Aplikasi. Manajemen PT Raja Grafindo Persada. Jakarta.

Hicking, C.F. 1971. Fish Culture. Faber and Faber. London. 317 pp.

Hidayat, A.S., dan B.D. Silvester. 1992. Biologi Kuda Laut. Direktorat Jenderal Perikanan. Balai Budidaya Laut Lampung. Lampung.

Hoar, W. S.. D.J. Randal, and J.R. Brett. 1979. Fish Physiology. Bioenergetics and Growth. Academic Press, Inc. London. Volume III.

Huet, M. 1978. Text Book Of Fish Culture : Breeding and Cultivation of Fish. Phoenix Press Inc. Queson City. Philipphines. 436 p.

Huisman, E.A. 1976. Food Conversion Efficiences at Maintenance and Production Level for Carp (Cyprinus carpio Linn.) and Rainbow Trout (Salmo gaidner Ric.). Aquaculture 9 (2) : 259-273.

Krebs. C.J. 1972. Ecology. The Experimental of Analysis of Distribution and Abudance. London. 894p.

Lockyear, J. 1988. Studi Pendahuluan Pemijahan di Bak Terkontrol dan Pembesaran Kuda Laut KNYSNA (Hippocampus capensis). Departement of Icthyology and Fisheries Science Rhodes University. Graham Stown. South Africa.

Mangampa, M., Burhanuddin dan H.S. Suwoyo. 2002. Studi Pendahuluan Penggunaan Air Tambak sebagai Media Pemeliharaan Juwana Kuda Laut (Hippocampus barbouri). Disampaikan pada Seminar Nasional Memacu Pengembangan Agribisnis 
JURNAL SAINTIFIK VOL.2 NO.2, JULI 2016

Melalui Optimalisasi Sumberdaya Lahan dan Penerapan Teknologi Spesifik Lokasi. Balai Penelitian Perikanan Pantai. Makassar, 22 - 23 Oktober 2002.

Maurice and R. Burton. 1983. Sea Horse. Departement of Ichthiology. American Museum of Natural History America.

NAFED. 1993. Buyers Guide to Indonesian Ornamental Fish. Published by Ministry of Trade. Indonesia.

Nontji, A. 1993. Laut Nusantara. Penerbit Djambatan. Jakarta.

Poernomo. 1988. Faktor Lingkungan Dominan pada Budidaya Udang Intensif. Seminar Budidaya Udang Intensif. Jakarta.

Sikong, M. 1982. Beberapa Faktor Lingkungan yang Mempengaruhi Produksi Biomassa Udang Windu (Panaeus monodon). Disertasi Fakultas Pasca Sarjana IPB. Bogor. 84 hal.

Simon and Schuster's. 1977. Guide to Freshwater and Marine Aquarium Fishes. A Fire Side Book. New York, London, Toronto.

Soeriatmadja, R.E. 1979. Ilmu Lingkungan. Departement Biology. Fakultas Pertanian. Institut Pertanian Bogor. Bogor.

Steffens, W. 1989. Principles of Fish Nutrition. Ellish Horwood Ltd. John Wiley and Sns. New York.

Sudaryanto. 1995. Copepoda sebagai Pakan Awal Juwana Kuda Laut (Hippocampus spp). Departemen Pertanian. Dirjen Perikanan. Balai Budidaya Laut Lampung. Buletin Budidaya laut No. 9 : 40-46

Sudaryanto, \& A.H. Al Qodri. 1993. Pemeliharaan Juwana Kuda Laut (Hippocampus spp) di bak Terkontrol. Departemen Pertanian. Dirjen Perikanan. Balai Budidaya Laut Lampung. Buletin Budidaya Laut No. 7 : 10-16.

Thayib, S.S. 1977. Beberapa Catatan yang Menarik Mengenai Tangkur Kuda (Hippocampus spp). Dalam Warta Oseana (6).

Vincent, A.C.J. 1996. Conservation in Action. Project Seahorse Teachers. Notes and Activity Sheets. Zoological Society of London. United Kingdom.

Vincent, A.C.J. 1998. The International Trade in Seahorse. TRAFFIC International, Cambridge. United Kingdom.

Weiping. 1990. Seahorse Culture in North China Salthpan. Shanghai China Aquaculture.

Yunus., I. Rusdi., K. Mahasetiawati dan T. Ahmad. 1994. Percobaan Pemeliharaan Larva Kepiting Bakau Scylla serrata pada Berbagai Padat Penebaran. Jurnal Penebaran Budidaya Pantai Vol 10 (1) : $19-26$

Zhang, B. 1994. Seahorse (Hippocampus) Culture in China In Aquaculture Technology of Marine Valuable Animals. Translated by Peter Chen. Southern Central China Industry University, pp $162-174$. 